\title{
Long-range beam-beam experiments in the Relativistic Heavy Ion Collider
}

\author{
R. Calaga, ${ }^{*}$ W. Fischer, and G. Robert-Demolaize \\ Brookhaven National Laboratory, Upton, New York 11973, USA \\ N. Milas \\ PSI, 5232 Villingen, Switzerland \\ (Received 18 April 2011; published 23 September 2011)
}

\begin{abstract}
Long-range beam-beam effects are a potential limit to the LHC performance with the nominal design parameters, and certain upgrade scenarios under discussion. To mitigate long-range effects, current carrying wires parallel to the beam were proposed and space is reserved in the LHC for such wires. Two current carrying wires were installed in the Relativistic Heavy Ion Collider to study the effect of strong long-range beam-beam effects in a collider, as well as test the compensation of a single long-range interaction. The experimental data were used to benchmark simulations. We summarize this work.
\end{abstract}

DOI: 10.1103/PhysRevSTAB.14.091001

PACS numbers: 29.20.D-, 29.27. $-\mathrm{a}$

\section{INTRODUCTION}

Beam-beam effects have limited the performance of previous and existing hadron colliders [1-3] such as the intersecting storage ring (ISR) [4-6], Spp $\mathrm{S}$ [7-10], Tevatron [11-13], and RHIC [14,15], and are also expected to limit the performance of the LHC [16-32].

Beam-beam effects can be categorized as either incoherent (dynamic aperture and beam lifetime), PACMAN (bunch-to-bunch variations), or coherent (beam oscillations and instabilities) [25]. These effects can be caused by both head-on and long-range interactions. Head-on effects, leading to tune shifts and spreads, are important in all hadron colliders. Total beam-beam induced tune shifts as large as 0.028 were achieved in the $\mathrm{Sp} \overline{\mathrm{p} S}$ [10] and Tevatron [13], although operational tune shift values are somewhat lower. The LHC in its early stages of commissioning has already reached a total head-on beam-beam tune shift of 0.02 [33].

Long-range effects, however, differ in previous and existing colliders. In the ISR the beams collided under a large crossing angle of $15 \mathrm{deg}$ [6] that greatly reduced longrange effects. In the Spp $S$, with both beams in the same aperture and only three bunches per beam, there were a few long-range interactions distributed over the ring circumference. Because of the difference in the bunch intensities, the effect on the antiprotons was stronger. In the Tevatron, also with both beams in the same aperture but 36 bunches per beam, there are more long-range interactions. With increased intensity of the antiproton bunches, protons can also be affected.

\footnotetext{
*rcalaga@bnl.gov
}

Published by the American Physical Society under the terms of the Creative Commons Attribution 3.0 License. Further distribution of this work must maintain attribution to the author(s) and the published article's title, journal citation, and DOI.
In RHIC (Fig. 1), where both beams share the same aperture only in the interaction regions, there is only one long-range interaction per interaction region without an experiment (a total of four in the current configuration), with a $10 \mathrm{~mm}$ separation (corresponding to $30 \mathrm{rms}$ beam sizes for protons at $250 \mathrm{GeV}$ energy). Long-range interactions have affected the RHIC ramp transmission in the past [14].

\section{LONG-RANGE EFFECTS AND COMPENSATION IN THE LHC}

In the LHC there are 32 long-range beam-beam interactions localized in each of four interaction regions [25]. A major upgrade of the LHC interactions region is foreseen by the end of the decade with the primary objective to

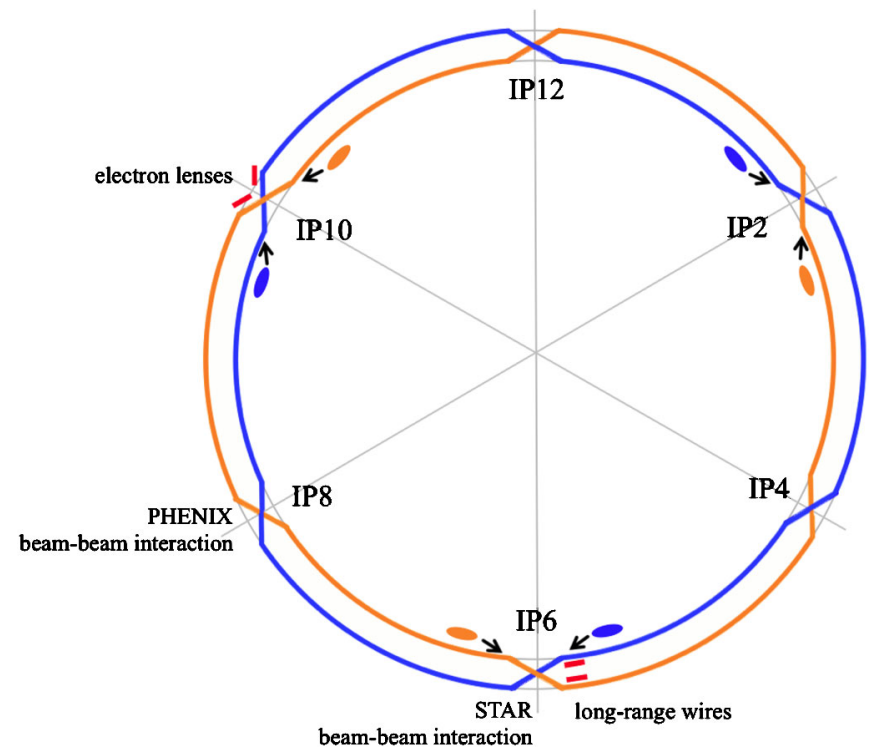

FIG. 1. Beam-beam interactions in RHIC and locations of wires and electron lenses. 
increase the average luminosity of the machine by about a factor of 5-10 above the design performance. Among the various upgrade scenarios a crab crossing scheme (CC), an early beam separation scheme (ES), and a large Piwinski angle (LPA) are considered. In the CC scheme, crab cavities placed on either side of the interaction region impart a transverse kick to effectively compensate the crossing angle. This scheme allows for a large crossing angle that greatly reduces long-range beam-beam effects. In the ES scheme [27,28], the number of long-range interactions is greatly reduced but four parasitic collisions at $4-5 \sigma$ per IP remain. In the LPA scheme [26] the small crossing angle will be maintained, and long bunches of intensities up to $4-5 \times 10^{11}$ protons are used. All schemes aim at higher than nominal bunch currents and reduced $\beta^{*}$. Therefore, long-range effects tend to become more problematic and require more aperture for larger crossing angles or compensation to mitigate these effects. The LPA scheme would most benefit from long-range beam-beam compensation.

The compensation of long-range effects in the Tevatron was proposed with electron lenses [34], and in the LHC with wires [35]. Electron lenses were also considered for the LHC [36], and the use of wires was also studied for the Tevatron [37]. Implementation of long-range beam-beam compensation in the Tevatron is challenging because the effect is distributed over the whole ring. In the LHC the effect is localized in the interaction regions. A partial longrange beam-beam compensation was successfully implemented in the $\mathrm{e}^{+} \mathrm{e}^{-}$collider DAФNE [38]. Beam-beam compensation and related issues were reviewed at a workshop in 2007 [39].

\section{RHIC AS A TEST BENCH FOR LONG-RANGE STUDIES}

Figures 1 and 3 show the basic layout of the beam-beam interaction and compensation studies in RHIC. At store there are nominally two head-on interactions in points 6 and 8 (IP6 and IP8), and long-range interactions with a large separation in the other interaction points. Three bunches in the Blue ring are coupled to three bunches in the Yellow ring through the head-on beam-beam interaction. For studies two DC wires were installed in the Blue and Yellow rings respectively in interaction region 6 (IR6). Table I shows the main beam parameters for polarized proton operation, both achieved and design. In RHIC the beam-beam effect is strongest in proton operation.

In the LHC locations in warm sections of the interaction regions are reserved to accommodate long-range beambeam wire compensators (Fig. 2), or electron lenses. These locations have about equal horizontal and vertical $\beta$ functions. With the expected strong long-range beambeam effects in the LHC, and the proposed wire compensation, experimental data and simulations of long-range effects are highly desirable. Operational and experimental data exist from the Spp̄S and the Tevatron. In the SPS,
TABLE I. Main RHIC parameters achieved in polarized proton operation that are relevant for beam-beam effects protons (2009). Note that the polarized proton bunch intensity is also limited by intensity dependent depolarization effects in the AGS.

\begin{tabular}{lccc}
\hline \hline Quantity & Unit & & \\
\hline Beam energy, $E_{b}$ & $\mathrm{GeV}$ & 100 & 250 \\
Bunch intensity, $N_{b}$ & $10^{11}$ & 1.35 & 1.1 \\
Norm emittance, $\epsilon$ & $\mu \mathrm{m}$ & 2.5 & 3.0 \\
rms bunch length, $\sigma_{z}$ & $\mathrm{~m}$ & 0.85 & 0.60 \\
Beam-beam parameter $\xi / \mathrm{IP}$ & $\ldots$ & 0.0056 & 0.0045 \\
Number of IPs & $\ldots$ & 2 & 2 \\
$\beta^{*}$ at IP6, IP8 & $\mathrm{m}$ & 0.7 & 0.7 \\
\hline \hline
\end{tabular}

wires were installed to further investigate strong longrange beam-beam interactions, to test the compensation scheme, and to benchmark simulations [30,40-42].

The wire experiments in RHIC complement these studies. The beam lifetime in RHIC is typical for a collider and better than in the SPS wire experiments. In addition, and unlike in the SPS, head-on effects can be included, and with properly placed long-range interactions and wires, the compensation of a single long-range interaction is possible.
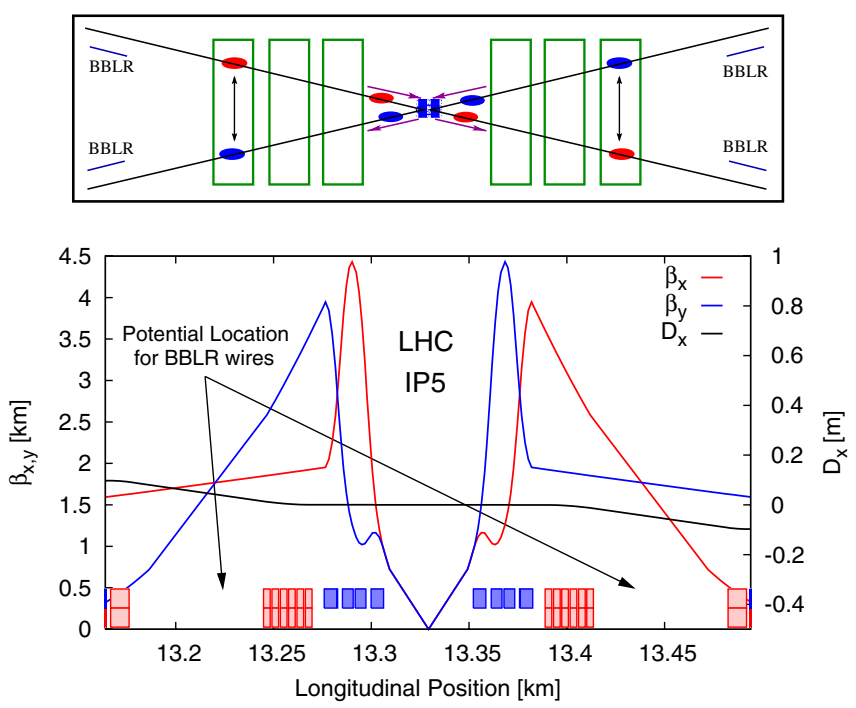

FIG. 2. LHC interaction region schematically showing the common focusing channel with the 32 long-range interactions on the left and the right of the collision point (top) and the optics functions in the region.

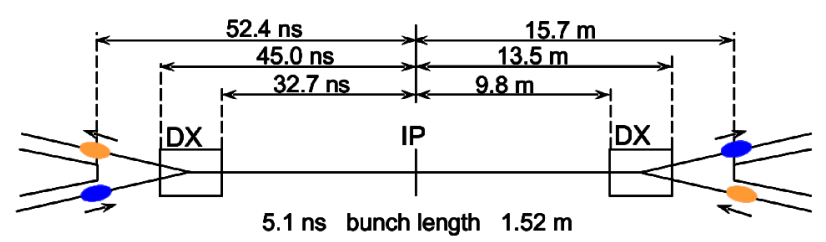

FIG. 3. Schematic of the RHIC interaction regions. 
TABLE II. Parameters for RHIC wires. The wire material is $\mathrm{Cu}$ at $20^{\circ} \mathrm{C}$. The nominal wire strength is for a single long-range interaction with a proton bunch intensity of $2 \times 10^{11}$.

\begin{tabular}{lcc}
\hline \hline Quantity & unit & Value \\
\hline Strength $(I L)$, nominal & $\mathrm{A} \mathrm{m}$ & 9.6 \\
Maximum strength $(I L)_{\max }$ & $\mathrm{A} \mathrm{m}$ & 125 \\
Length of wire $L$ & $\mathrm{~m}$ & 2.5 \\
Radius of wire $r$ & $\mathrm{~mm}$ & 3.5 \\
Number of heat sinks $n$ & $\ldots$ & 3 \\
Electrical resistivity $\rho_{e}$ & $\Omega \mathrm{m}$ & $1.72 \times 10^{-8}$ \\
Heat conductivity $\lambda$ & $\mathrm{W} \mathrm{m}^{-1} \mathrm{~K}^{-1}$ & 384 \\
Thermal expansion coefficient & $\mathrm{K}^{-1}$ & $1.68 \times 10^{-5}$ \\
Radius of existing pipe $r_{p}$ & $\mathrm{~mm}$ & 60 \\
Current $I$, nominal & $\mathrm{A}$ & 3.8 \\
Maximum current $I_{\max }$ & $\mathrm{A}$ & 50 \\
Current ripple $\Delta I / I$ (at $50 \mathrm{~A})$ & $10^{-4}$ & $<1.7$ \\
Electric resistance $R$ & $\mathrm{~m} \Omega$ & 1.12 \\
Maximum voltage $U_{\max }$ & $\mathrm{mV}$ & 55.9 \\
Maximum power $P_{\max }$ & $\mathrm{W}$ & 2.8 \\
Maximum temperature change $\Delta T_{\max }$ & $\mathrm{K}$ & 15 \\
Maximum length change $\Delta L_{\max }$ & $\mathrm{mm}$ & 0.4 \\
Vertical position range & $\mathrm{mm} / \sigma_{y}$ & $65 / 10.6$ \\
\hline \hline
\end{tabular}

\section{WIRES IN RHIC}

The RHIC wire design is based on experience gained with the SPS units. Design considerations are the location in ring, the integrated strength $(I L)$, the wire temperature $T$ in operation, the positioning range and accuracy, power supply requirements, controls, and diagnostics [43,44]. The wire parameters are shown in Table II.

\section{A. Location in the ring}

For a successful compensation, the phase advance between the long-range interaction and the compensator should be no larger than about 10 degrees [45]. Lattices with $\beta^{*} \leq 1.0 \mathrm{~m}$ have such small phase advances between the entrance to the DX and the exit of Q3. Thus it is possible to place a wire in the warm region after Q3 to compensate for a long-range beam-beam interaction near the DX magnet (Fig. 4). Since the beam paths must cross horizontally, it is easier to control the distance between the beams in an experiment through vertical separation. To compensate for a vertical long-range interaction near the DX magnet, one wire can be installed in each ring (see Fig. 5). In the Blue ring the wire is installed below the beam axis, in the Yellow ring above the beam axis.

\section{B. Integrated strength}

To compensate a single long-range interaction, the compensator's integrated strength $(I L)$ must be the same as the opposing bunch's current integrated over its length $(I L)=$ $N_{b} e c$, where $I$ is the current in the wire, $L$ its length, $N_{b}$ the bunch intensity, $e$ the elementary charge, and $c$ the speed of light (see Table II).

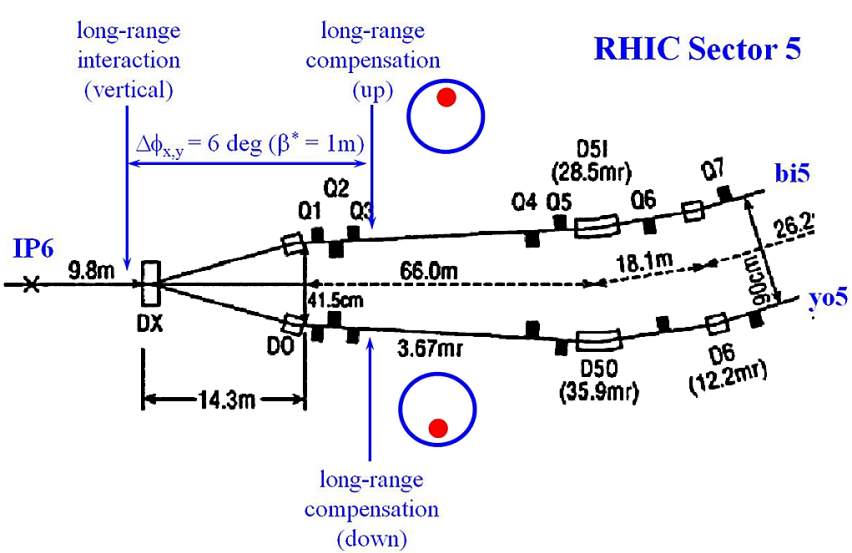

FIG. 4. Location of wires in RHIC and location of long-range beam-beam interaction for compensation.

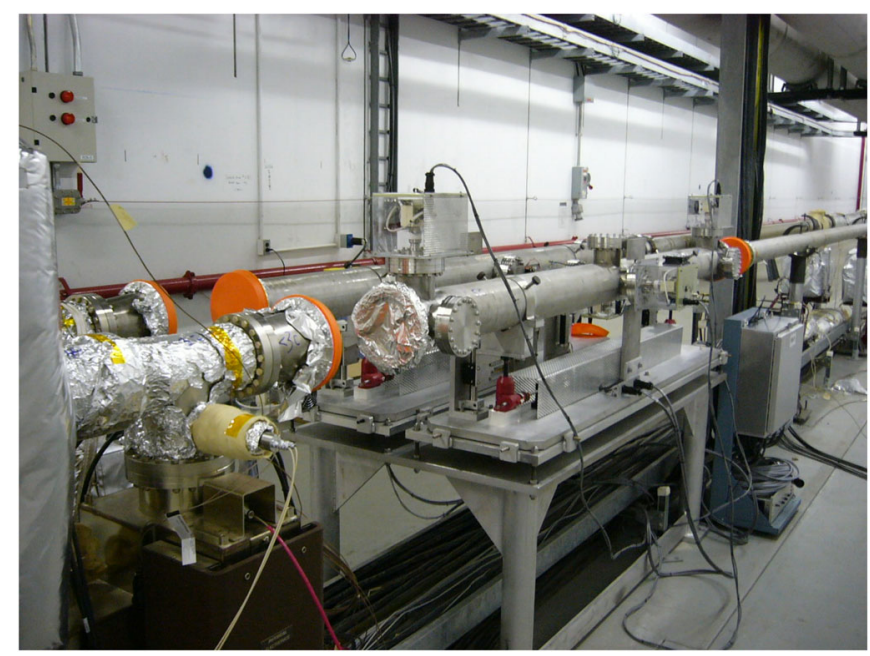

FIG. 5. The two long-range beam-beam wires in the RHIC tunnel during installation.

In the LHC, an integrated strength of $80 \mathrm{~A} \mathrm{~m}$ is required to correct for the 16 long-range interactions on either side of an IR [35]. Such a strength is also expected to lead to enhanced diffusion at amplitudes larger than six rms transverse beam sizes [45]. To study the enhanced diffusion in RHIC, the wire is designed for $(I L)_{\max }=125 \mathrm{~A} \mathrm{~m}$.

\section{Wire temperature}

The wire temperature should not exceed $100^{\circ} \mathrm{C}$ to avoid increased outgassing of the vacuum components. We use a number of air cooled heat sinks to limit the wire temperature.

Assume first a wire in vacuum of radius $r$ and length $l$, with electrical resistivity $\rho_{e}$ and heat conductivity $\lambda$. A current $I$ flows through the wire, and at both ends there are heat sinks that maintain the temperature $T_{0}$. Further we assume that the temperature rise $\Delta T$ in the wire is small enough so that the material coefficients $\rho_{e}$ and $\lambda$ are constants. In each length element $d x$ heat $d Q$ is produced through the wire's resistivity at the rate 


$$
\frac{d Q}{d t}=\rho_{e} \frac{d x}{\pi r^{2}} I^{2},
$$

and the heat flow is connected to the temperature gradient $d T(x) / d x$ via the heat equation

$$
\frac{d Q}{d t}=-\lambda \pi r^{2} \frac{d T}{d x}
$$

Combining Eqs. (1) and (2) yields the differential equation for the temperature

$$
\frac{d T^{2}(x)}{d x^{2}}=-\frac{\rho_{e}}{\lambda} \frac{I^{2}}{\pi^{2} r^{4}}
$$

with the solution

$$
T(x)=-\frac{1}{2 \pi^{2}} \frac{\rho_{e}}{\lambda} \frac{I^{2}}{r^{4}} x^{2}+a x+b .
$$

The coefficients $a$ and $b$ can be determined from the boundary conditions $T(0)=T(l)=T_{0}$ yielding

$$
T(x)=T_{0}+\frac{1}{2 \pi^{2}} \frac{\rho_{e}}{\lambda} \frac{I^{2}}{r^{4}}\left(x l-x^{2}\right) .
$$

The maximum temperature increase $\Delta T_{\max }$ is in the center of the wire, $x=l / 2$, and is

$$
\Delta T_{\max }=\frac{1}{8 \pi^{2}} \frac{\rho_{e}}{\lambda} \frac{(I l)^{2}}{r^{4}} .
$$

If we now assume a wire of length $L$ with $n$ heat sinks, we can replace $l$ by $L /(n-1)$ in Eq. (6) and arrive at

$$
\Delta T_{\max }=\frac{1}{8 \pi^{2}} \frac{\rho_{e}}{\lambda} \frac{(I L)^{2}}{(n-1)^{2} r^{4}} .
$$

We use $n=3$ heat sinks cooled with forced air. To move the wire compensator close to the beam, its radius should not be much larger than an rms transverse beam size. The calculated temperature change is shown in Table II. Figure 6 shows a drawing of the end of a wire. Visible

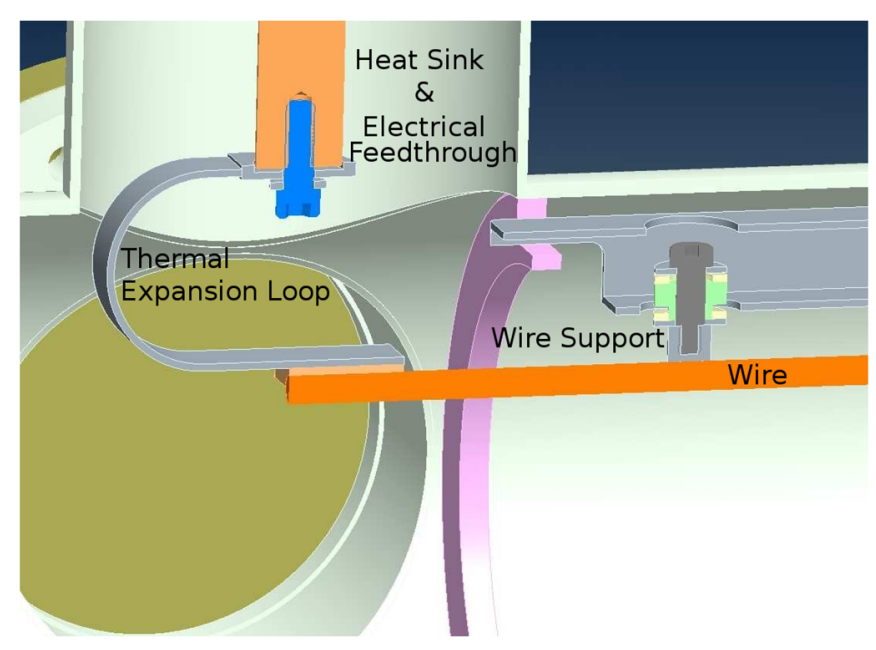

FIG. 6. Drawing of the end of a long-range beam-beam wire in RHIC. are the wire support, the electrical feedthrough which is also a heat sink, and a connecting loop allowing for thermal expansion of the wire.

\section{Power supply requirements}

To limit emittance growth, a current ripple of $\Delta I / I<10^{-4}$ is required [45]. A measurement shows a current ripple of $\Delta I / I<1.7 \times 10^{-4}$ where the upper limit is given by the noise floor of the current measurement.

\section{LONG-RANGE EXPERIMENTS AT RHIC}

More than 30 dedicated long range (LR) beam-beam experiments were performed at different energies, with different species and various machine configurations [46]. They span a variety of long-range conditions which help benchmark simulations tools. The main parameters that were varied were the strength of the long-range interactions (wire current), the distance between the beam and the wire (or other beam), the tune and chromaticity. All experimental sessions to study long-range beam-beam interactions in RHIC can be broadly classified into three categories approximately in chronological order: (i) measurement of a single long-range interaction between the two proton bunches at 23 and $100 \mathrm{GeV}$ in IP6; (ii) effect of the DC wires on a single beam either by varying the current at a fixed distance or varying the distance to the beam with fixed current on both protons at $100 \mathrm{GeV}$ and gold at $100 \mathrm{GeV} /$ nucleon; (iii) effect of long-range interaction either with a wire in the presence of head-on collisions or long-range interactions between the two beams in IP6 with simultaneous compensation using a wire at $100 \mathrm{GeV}$.

A summary of all long-range experiments performed in the RHIC accelerator between 2005 to 2009 are listed with corresponding beam conditions in Table III. The main observables in long-range beam-beam experiments are orbits, tunes, beam transfer functions, and the beam lifetime. Several simulations were performed for a subset of measurements which show successful reconstruction of all measurable quantities and the onset of losses [47]. Specific examples for each of the three categories with detailed results are presented in the next sections to summarize all the long-range experiments performed at RHIC.

\section{A. Single long-range measurements}

The first set of long-range beam-beam, experiments were performed with proton beams in 2006. The motivation of these experiments was to characterize the effect of one parasitic interaction on beam losses for a future compensation demonstration. The Blue and Yellow beams were vertically separated in the IR6 region close to the DX magnet (Fig. 3). The RHIC beams are very stable at the nominal working point and the effect of a single long-range (weak effect) is not visible in the beam lifetime. An effect 
TABLE III. Summary of long-range beam-beam experiments in RHIC. The wires in the Blue and Yellow ring are named B-BBLR and Y-BBLR, respectively. Fields are left blank when the experimental value could not be determined.

\begin{tabular}{|c|c|c|c|c|c|c|c|c|c|c|c|c|c|}
\hline $\begin{array}{l}\text { Fill } \\
\text { number }\end{array}$ & Ring & Scan & Species & Relative $\gamma$ & $\begin{array}{r}\text { Bunches } \\
\gamma \text { per ring }\end{array}$ & $Q_{x}$ & $Q_{y}$ & LR location & $\begin{array}{l}\text { LR strength } \\
\qquad \begin{array}{l}(I L) \\
\text { A m }\end{array}\end{array}$ & $\begin{array}{l}\text { LR separation } \\
\qquad \begin{array}{l}d \\
\sigma\end{array}\end{array}$ & $\begin{array}{c}\begin{array}{c}\text { Fitted } \\
\text { exponen }\end{array} \\
p\end{array}$ & $\begin{array}{c}d \text { for } \\
<20 \mathrm{~h} \\
\sigma\end{array}$ & Comment \\
\hline \multicolumn{14}{|l|}{2005} \\
\hline 6981 & $\mathrm{~B}$ & 1 & $\mathrm{p}$ & 25.963 & 1 & 0.7331 & 0.7223 & IP4 & 5.3 & B moved & & & Weak signal \\
\hline 6981 & $\mathrm{Y}$ & 1 & $\mathrm{p}$ & 25.963 & 1 & 0.7267 & 0.7234 & IP4 & 5.3 & B moved & & & Weak signal \\
\hline 6981 & $\mathrm{~B}$ & 2 & $\mathrm{p}$ & 25.963 & 1 & 0.7351 & 0.7223 & IP4 & 5.8 & B moved & & & Weak signal \\
\hline 6981 & $\mathrm{Y}$ & 2 & $\mathrm{p}$ & 25.963 & 1 & 0.7282 & 0.7233 & IP4 & 5.8 & B moved & & & Weak signal \\
\hline 6981 & $\mathrm{~B}$ & 3 & $\mathrm{p}$ & 25.963 & 1 & 0.7383 & 0.7247 & IR4 DX & 8.6 & Y moved & & & Weak signal \\
\hline 6981 & $\mathrm{Y}$ & 3 & $\mathrm{p}$ & 25.963 & 1 & 0.7271 & 0.7218 & IR4 DX & 8.6 & $\mathrm{Y}$ moved & & & Weak signal \\
\hline 6981 & $\mathrm{~B}$ & 4 & $\mathrm{p}$ & 25.963 & 1 & 0.7394 & 0.7271 & IR4 DX & 8.9 & Y moved & 4.9 & 6.5 & \\
\hline 6981 & $\mathrm{Y}$ & 4 & $\mathrm{p}$ & 25.963 & 1 & 0.7264 & 0.7388 & IR4 DX & 8.9 & Y moved & 2.8 & & \\
\hline \multicolumn{14}{|c|}{ 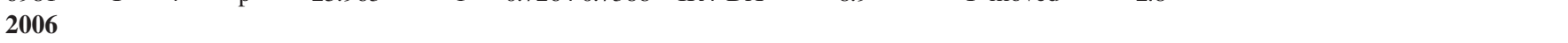 } \\
\hline 7707 & $\mathrm{~B}$ & 1 & $\mathrm{p}$ & 106.597 & 10 & & & IR6 DX & 6.7 & B moved & & & Weak signal \\
\hline 7707 & $\mathrm{Y}$ & 1 & $\mathrm{p}$ & 106.597 & 10 & & & IR6 DX & 6.7 & B moved & & & Weak signal \\
\hline 7707 & B & 2 & $\mathrm{p}$ & 106.597 & 10 & & & IR6 DX & 6.7 & Y moved & & & Weak signal \\
\hline 7707 & $\mathrm{Y}$ & 2 & $\mathrm{p}$ & 106.597 & 10 & & & IR6 DX & 6.7 & $\mathrm{Y}$ moved & & & Weak signal \\
\hline 7747 & $\mathrm{~B}$ & 1 & $\mathrm{p}$ & 106.597 & 8 & & & IR6 DX & 7.9 & B moved & & & Weak signal \\
\hline 7747 & $\mathrm{Y}$ & 1 & $\mathrm{p}$ & 106.597 & 10 & & & IR6 DX & 7.9 & B moved & & & Weak signal \\
\hline 7747 & $\mathrm{~B}$ & 2 & $\mathrm{p}$ & 106.597 & 8 & & & IR6 DX & 7.0 & Y moved & & & Weak signal \\
\hline 7747 & $\mathrm{Y}$ & 2 & $\mathrm{p}$ & 106.597 & 10 & & & IR6 DX & 7.0 & $\mathrm{Y}$ moved & & & Weak signal \\
\hline 7807 & $\mathrm{~B}$ & 1 & $\mathrm{p}$ & 106.597 & 12 & 0.6912 & 0.6966 & IR6 DX & 8.2 & Y moved & 2.5 & 3.5 & $\begin{array}{l}\text { Additional } \\
\text { octupoles }\end{array}$ \\
\hline 7807 & $\mathrm{Y}$ & 1 & $\mathrm{p}$ & 106.597 & 12 & 0.7092 & 0.6966 & IR6 DX & 8.2 & Y moved & 1.5 & 3.5 & $\begin{array}{l}\text { Additional } \\
\text { octupoles }\end{array}$ \\
\hline \multicolumn{14}{|l|}{2007} \\
\hline 8231 & B & 1 & $\mathrm{Au}$ & 10.520 & 6 & 0.2327 & 0.2141 & B-BBLR & 12.5 & B-BBLR moved & 7.2 & 6.5 & \\
\hline 8231 & $\mathrm{~B}$ & 1 & $\mathrm{Au}$ & 10.520 & 6 & 0.2322 & 0.2140 & B-BBLR & 125 & B-BBLR moved & 7.8 & 9.0 & \\
\hline 8405 & $\mathrm{~B}$ & 1 & $\mathrm{Au}$ & 107.369 & 56 & 0.2260 & 0.2270 & B-BBLR & 125 & B-BBLR moved & 1.7 & 15.0 & $\begin{array}{l}\text { Background } \\
\text { test }\end{array}$ \\
\hline 8609 & B & 1 & $\mathrm{Au}$ & 107.369 & 23 & 0.2340 & 0.2260 & B-BBLR & 12.5 & B-BBLR moved & 7.4 & 6.0 & \\
\hline 8609 & $\mathrm{~B}$ & 2 & $\mathrm{Au}$ & 107.369 & 23 & 0.2340 & 0.2260 & B-BBLR & 125 & B-BBLR moved & 16.0 & 5.5 & \\
\hline 8609 & $\mathrm{Y}$ & 1 & $\mathrm{Au}$ & 107.369 & 23 & 0.2280 & 0.2350 & Y-BBLR & 12.5 & Y-BBLR moved & 4.8 & 9.5 & \\
\hline 8609 & $\mathrm{Y}$ & 2 & $\mathrm{Au}$ & 107.369 & 23 & 0.2280 & 0.2350 & Y-BBLR & 125 & Y-BBLR moved & 4.1 & 7.5 & \\
\hline 8727 & $\mathrm{~B}$ & 1 & $\mathrm{Au}$ & 107.369 & 23 & 0.2200 & 0.2320 & B-BBLR & 12.5 & B-BBLR moved & 5.2 & 9.5 & \\
\hline 8727 & $\mathrm{~B}$ & 2 & $\mathrm{Au}$ & 107.369 & 23 & 0.2200 & 0.2320 & B-BBLR & 125 & B-BBLR moved & 8.1 & 10.0 & \\
\hline 8727 & $\mathrm{~B}$ & 1 & $\mathrm{Au}$ & 107.369 & 23 & 0.2320 & 0.2280 & Y-BBLR & 12.5 & Y-BBLR moved & 6.3 & 4.5 & \\
\hline 8727 & $\mathrm{~B}$ & 2 & $\mathrm{Au}$ & 107.369 & 23 & 0.2320 & 0.2280 & Y-BBLR & 125 & Y-BBLR moved & 10.8 & 5.0 & \\
\hline 8727 & $\mathrm{~B}$ & 3 & $\mathrm{Au}$ & 107.369 & 23 & 0.2320 & 0.2280 & Y-BBLR & $125-0$ & -6.5 & & & \\
\hline 8727 & $\mathrm{~B}$ & 4 & $\mathrm{Au}$ & 107.369 & 23 & 0.2320 & 0.2280 & Y-BBLR & 125 & -6.5 & & & vertical chromaticity $2-8$ \\
\hline 8727 & $\mathrm{~B}$ & 5 & $\mathrm{Au}$ & 107.369 & 23 & 0.2320 & 0.2280 & Y-BBLR & $125-0$ & -6.5 & & & ver. chromaticity 8 \\
\hline \multicolumn{14}{|c|}{ 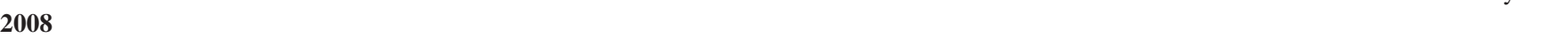 } \\
\hline 9664 & $\mathrm{~B}$ & 1 & d & 107.369 & 12 & 0.2288 & 0.2248 & B-BBLR & 125 & B-BBLR moved & 3.8 & 17.0 & $\begin{array}{c}\text { End of physics } \\
\text { store }\end{array}$ \\
\hline 9664 & $\mathrm{~B}$ & 2 & $\mathrm{~d}$ & 107.369 & 12 & 0.2288 & 0.2248 & B-BBLR & $75-125$ & 5.8 & & & $\begin{array}{c}\text { End of physics } \\
\text { store }\end{array}$ \\
\hline \multicolumn{14}{|l|}{2009} \\
\hline 10793 & $\mathrm{~B}$ & $\cdots$ & $\mathrm{p}$ & 106.597 & 36 & 0.691 & 0.688 & B-BBLR & 125 & B-BBLR moved & & & $\begin{array}{l}\text { With head-on } \\
\text { collisions }\end{array}$ \\
\hline 10793 & $\mathrm{Y}$ & $\cdots$ & $\mathrm{p}$ & 106.597 & 36 & 0.695 & 0.692 & Y-BBLR & 125 & Y-BBLR moved & & & $\begin{array}{l}\text { With head-on } \\
\text { collisions }\end{array}$ \\
\hline 10793 & B & $\cdots$ & $\mathrm{p}$ & 106.597 & 36 & 0.691 & 0.688 & IR6 DX & 12.5 & B-BBLR moved & & & LR compensation \\
\hline 10793 & $\mathrm{Y}$ & $\cdots$ & $\mathrm{p}$ & 106.597 & 36 & 0.695 & 0.692 & IR6 DX & 12.5 & Y-BBLR moved & & & LR compensation \\
\hline
\end{tabular}

of a compensation effect will not be possible to detect with the available instrumentation.

Therefore, a finite strength in lattice octupoles and a working point close to the 10th order resonance as shown in Fig. 7 is chosen. At this modified working point, the beams are marginally stable as the introduction of the single parasitic interaction increases the tune spread of the large amplitude particles on to the 10th order 


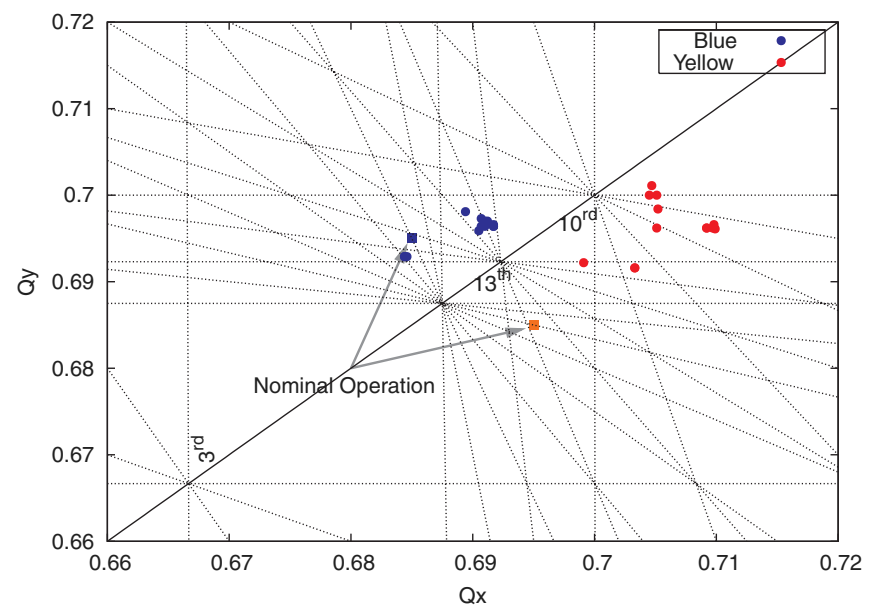

FIG. 7. Tunes in the resonance diagram for both beams and both planes during a scan.

resonance, thus enhancing the effect. This setup of marginally stable beams is only used for experiments with single long-range interaction between the two beams. Some relevant lattice and beam parameters are listed in Table IV. The marginally stable beams were essential as the effect of the single long-range interaction on the rather stable RHIC beams is subtle. In one such experiment, the effect on the beam losses on both beams as a function of the separation is shown in Fig. 8. To increase the signal-tonoise ratio the losses are averaged over the 12 bunches.

Note that the Yellow beam was moved while the Blue beam was kept stationary. Therefore, the effect on the Blue beam is of relevance as the losses in the Yellow beam may also be affected by orbit and tunes shifts. A small effect is visible when the beams are approximately $5 \sigma$ or closer.

Compensation of such small effects is difficult as the losses are smaller than the natural reproducibility of the machine for a given beam setup. Therefore, it was important to significantly enhance the loss due to the long-range interactions to clearly demonstrate compensation with a DC wire. Increased chromaticity and introduction of headon collisions were utilized to enhance the effect of the LR interaction with the DC wires [47].

TABLE IV. RHIC parameters for experiments with long-range interactions with proton beams.

\begin{tabular}{lcccc}
\hline \hline Quantity & Unit & Blue & Yellow \\
\hline Beam energy $E$ & $\mathrm{GeV} / \mathrm{n}$ & \multicolumn{2}{c}{100} \\
Rigidity $(B \rho)$ & $\mathrm{T} \mathrm{m}$ & \multicolumn{2}{c}{831.8} & \multicolumn{2}{c}{12} \\
Number of bunches & $\ldots$ & \multicolumn{2}{c}{10.6} & \multicolumn{2}{c}{$15-20$} \\
LR interaction from IP6 & $\mathrm{m}$ & \multicolumn{2}{c}{105} & \\
Normal emittances $\left(\epsilon_{x, y}\right)$ & $\mu \mathrm{m}$ & $\mathrm{m}$ & \multicolumn{2}{c}{$0.71 / 0.69$} \\
$\beta_{x}$ at wire location & $\ldots$ & $0.69 / 0.7$ & 342 \\
Tunes $\left(Q_{x, y}\right)$ & $\mathrm{m}$ & 1060 & 1000 \\
$\beta_{x}$ at wire location & $\mathrm{m}$ & 357 & \\
$\beta_{y}$ at wire location & $\mathrm{m}^{-2}$ & $6.3 \times 10^{-3}$ & \\
Octupule strength $(\mathrm{kl})$ & \multicolumn{4}{cc}{} \\
\hline \hline
\end{tabular}

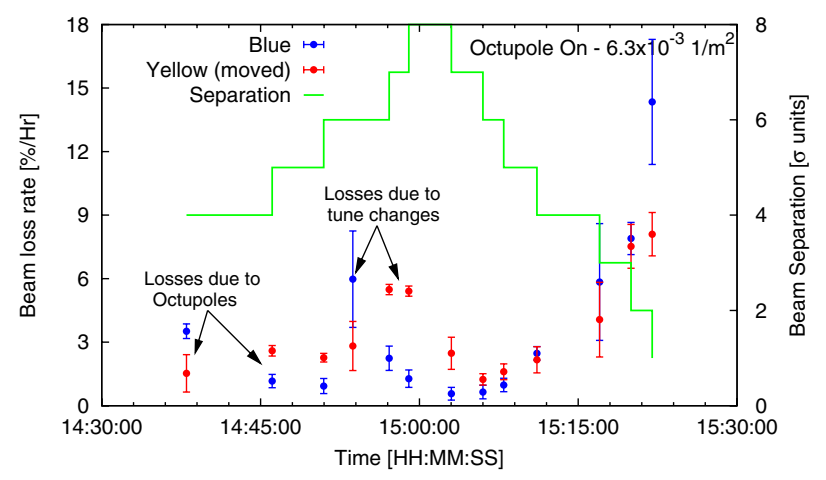

FIG. 8. Beam losses due to a single parasitic interaction of the Blue and Yellow beam. The Yellow beam moved closer to the Blue beam from an initially large separation.

\section{B. Wire scans on single beam}

After the installation of the DC wires in 2007, the majority of the experiments were carried out using the individual wires of the Blue and the Yellow ring to characterize the onset of the losses under certain beam conditions $[44,47]$. Most of the wire experiments were done with gold beams. Table $\mathrm{V}$ shows the main beam parameters for the wire experiments at store with gold beams.

The $\beta$ functions in Table $\mathrm{V}$ are the best estimate of the real $\beta$ functions in the machine. The design lattice has $\beta^{*}=0.8 \mathrm{~m}$ at IP6. To calculate the $\beta$ functions at the wire location we use $\beta^{*}=0.9 \mathrm{~m}$, and assume a $10 \%$ error. Figure 9 shows the MAD lattice near the interaction region 6 where the wires are located.

The measurements consisted mainly of distance and current scans and simultaneous measurements of the beam loss rate. An overview of the beam losses and wire position for the Blue and the Yellow ring during the course of a scan (fill 8727) is illustrated in Fig. 10. The beam loss rates are clearly different for the Blue and Yellow beams. This indicates towards different diffusion rates and repopulation of tails for the two beams. The exact reason for this difference is not identified. It should be noted that the wire installations are identical.

TABLE V. RHIC parameters for experiments with DC wires on individual gold beams.

\begin{tabular}{lccc}
\hline \hline Quantity & Unit & Blue & Yellow \\
\hline Beam energy $E$ & $\mathrm{GeV} /$ nucleon & \multicolumn{2}{c}{100} \\
Rigidity $(B \rho)$ & $\mathrm{Tm}$ & \multicolumn{2}{c}{831.8} \\
Number of bunches & $\ldots$ & \multicolumn{2}{c}{$6-56$} \\
Normal emittance $\epsilon_{x, y}$ & $\mu \mathrm{rad}$ & 17 & 17 \\
Distance IP6 to wire center & $\mathrm{m}$ & \multicolumn{2}{c}{40.92} \\
Parameter $K$ (at 50 A) & $\mathrm{nm}$ & \multicolumn{2}{c}{-30.1} \\
Horizontal tune $Q_{x}$ & $\ldots$ & 28.234 & 28.228 \\
Horizontal tune $Q_{y}$ & $\ldots$ & 28.226 & 29.235 \\
$\beta_{x}$ at wire location & $\mathrm{m}$ & 1091 & 350 \\
$\beta_{y}$ at wire location & $\mathrm{m}$ & 378 & 1067 \\
\hline \hline
\end{tabular}




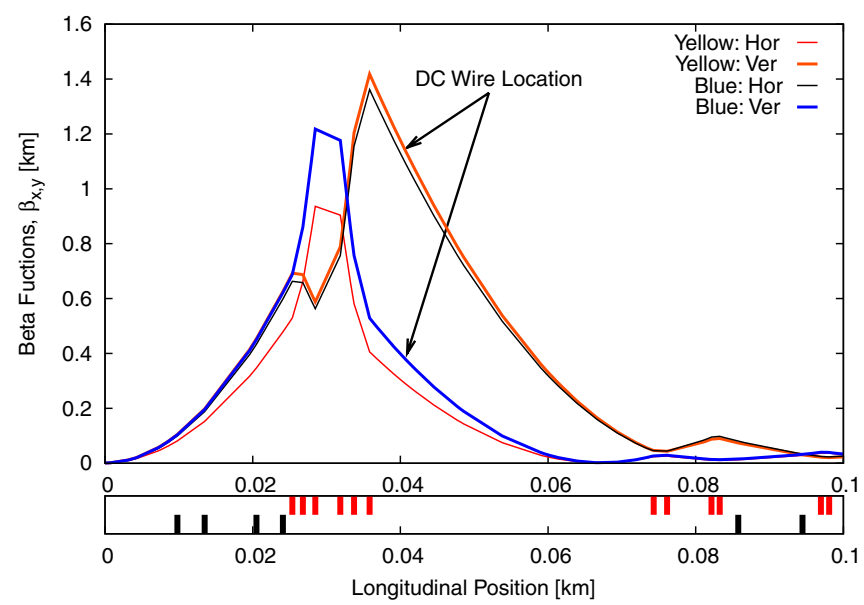

FIG. 9. The beta functions from MAD lattice for both rings as a function of longitudinal position.
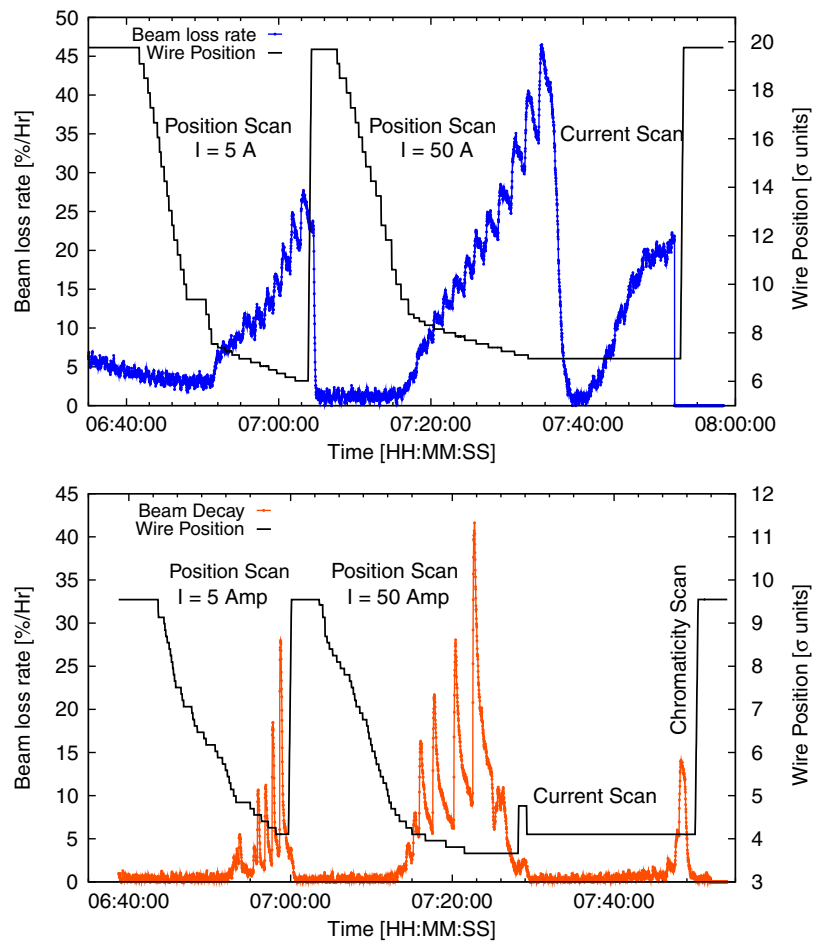

FIG. 10. Beam losses and wire position as a function of time during the course of position and current scan (May 2007, fill 8727).

Orbit, tune, and chromaticity changes can be calculated as a function of the long-range strength and distance [48]. These quantities and beam transfer functions are usually recorded to benchmark with theory and simulations. The vertical dipole kick $\Delta y^{\prime}$ and vertical tune change $\Delta Q_{y}$ due to the wire for a separation $d$ in the vertical plane between the beam and the wire are given by (assume no horizontal separation)

$$
\Delta y^{\prime}=\frac{K}{d} \quad \text { and } \quad \Delta Q_{x, y}= \pm \frac{K \beta_{x, y}}{4 \pi} \frac{1}{d^{2}}
$$

with

$$
K=\frac{\mu_{0}(I L)}{2 \pi(B \rho)} .
$$

$d$ is the distance between wire and the beam, $\mu_{0}$ the permeability of the vacuum, $(I L)$ the integrated wire strength, and $(B \rho)$ the beam rigidity.

Note that we take a positive sign for $d$ for a wire above the beam, and a negative sign below the beam. We also assume that reference vertical orbit position at the location of the wire is zero $\left(y_{\text {ref }}=0\right)$ for the wire current off. The sign of $K$ depends on the direction of the wire current relative to the beam direction, and the charge of the beam particles. In our case the wire current has the opposite direction to the beam, the Blue wire is above and the Yellow wire below the beam, and the beam particles have positive charges. In this case the sign of $K$ is negative in Blue, and positive in Yellow. The orbit change $\Delta y$ at the location of the wire due to the dipole kick $\Delta y^{\prime}$, for $\Delta y \ll d$, is then

$$
\Delta y=\frac{K \beta_{y}}{2 d} \frac{\cos \left(\pi Q_{y}\right)}{\left|\sin \left(\pi Q_{y}\right)\right|} .
$$

If the wire comes close to the beam Eq. (10) becomes inaccurate and needs to be replaced by

$$
\Delta y=\frac{d}{2}-\sqrt{\frac{d^{2}}{4}-\frac{1}{2} K \beta_{y} \cot \left(\pi Q_{y}\right)},
$$

where now $d$ is the distance between the wire and the beam position at zero wire current.

Orbit and tune changes agree with expectations under well controlled experimental circumstances [47,49]. Figure 11 shows a comparison of the measured beam

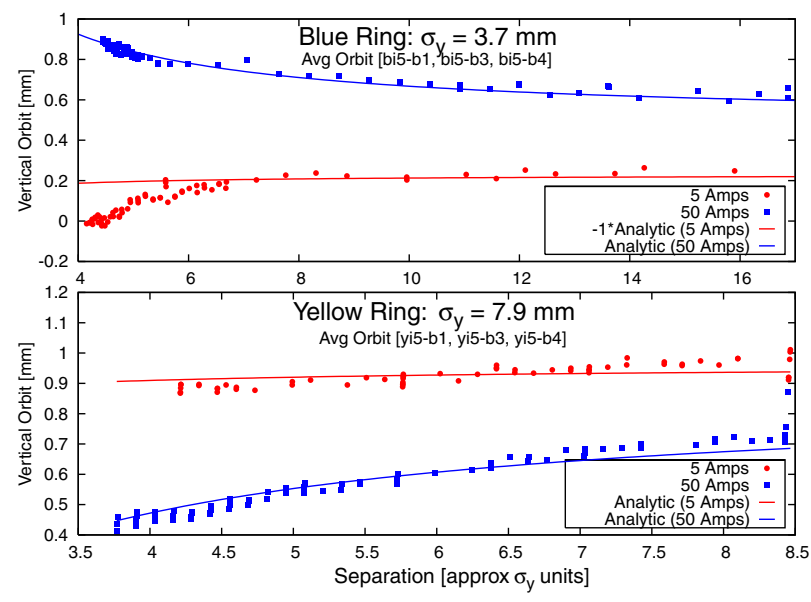

FIG. 11. Vertical orbit change (average of three beam position monitors near wire) as a function of vertical distance, in Blue and Yellow ring at $5 \mathrm{~A}$ and $50 \mathrm{~A}$. Solid lines in all plots represent the analytical prediction. 


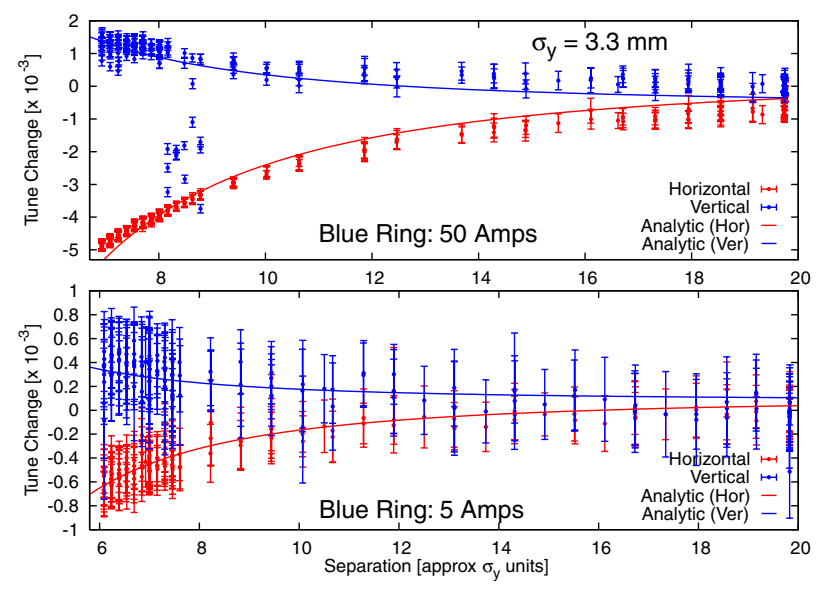

FIG. 12. Horizontal and vertical tune change for $50 \mathrm{~A}$ and $5 \mathrm{~A}$ wire current, for the Blue ring. Solid lines in all plots represent the analytical prediction.

trajectories to the analytical prediction as a function of the separation between the wire and the Blue beam.

Figure 12 shows a comparison of the measured tunes to the analytical prediction as a function of the separation between the wire and the beam.

The beam lifetime, however, is determined through the nonlinear beam-beam effect and can only be assessed in detailed simulations. Figure 13 (top) shows the beam loss rate as a function of the vertical wire distance to the beam. The onset of losses due to a long-range type interaction between the wire and the beam is visible. Similarly the effect on beam losses due to a current scan at a fixed distance is shown in Fig. 13 (bottom). The approximate separation in the Blue ring is $9 \sigma$ and in the Yellow ring is $5 \sigma$. The yellow ring shows very weak or no effect with a current scan which is probably due to a previous distance scan resulting in a cleaning of the large amplitude particles.

It was speculated that the beam lifetime $\tau$ can be expressed as $\tau=A d^{p}$, where $A$ is an amplitude, $d$ the distance between wire and beam, and $p$ an exponent that would typically be in a narrow range. For the SPS $p$ had been found to be about 5 , and for the Tevatron to be about 3 [50]. In Table III the fitted exponents are listed for all cases for which a fit was possible. The fitted exponents range from 1.7 to 16 , i.e. $p$ is not constrained within a narrow range. 10 of the $13 p$ values are between 4 and 10 . Figure 14 shows the fitted exponents $p$ as a function of the ion tunes in the upper part, and the proton tunes in the lower part. Ion tunes near the diagonal and away from either horizontal or vertical resonances show smaller exponents $p$. The experiments also showed that the beam lifetime is reduced with increased chromaticity [47].

Another simple measure of assessing the long-range beam-beam effect in experiments is the distance between the beam and wire (or other beam) at which the beam lifetime become smaller than a certain value. We have chosen this value to be $20 \mathrm{~h}$, which would imply a
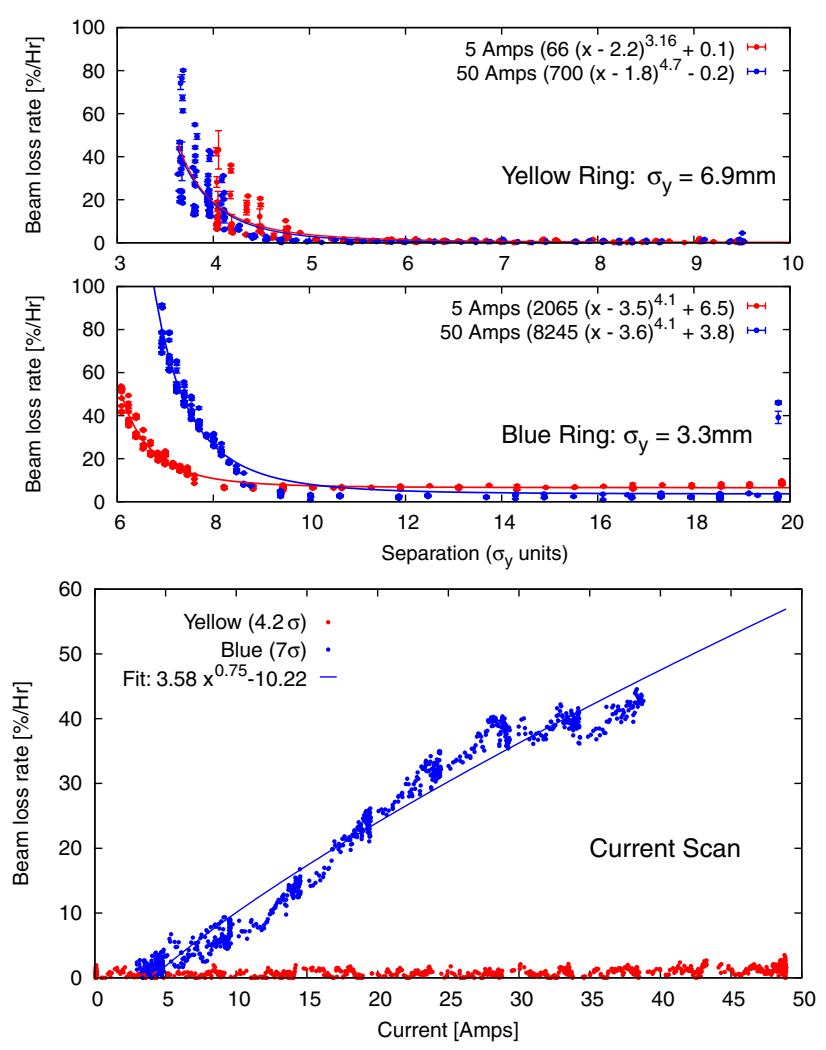

FIG. 13. Top: Beam loss as a function of the DC wire separation to the Blue and the Yellow beams at $5 \mathrm{~A}$ and $50 \mathrm{~A}$. Bottom: Beam loss due to a current scan in the DC wire fixed at a given distance from the beam. Solid lines in all plots show a power law fit to the losses.
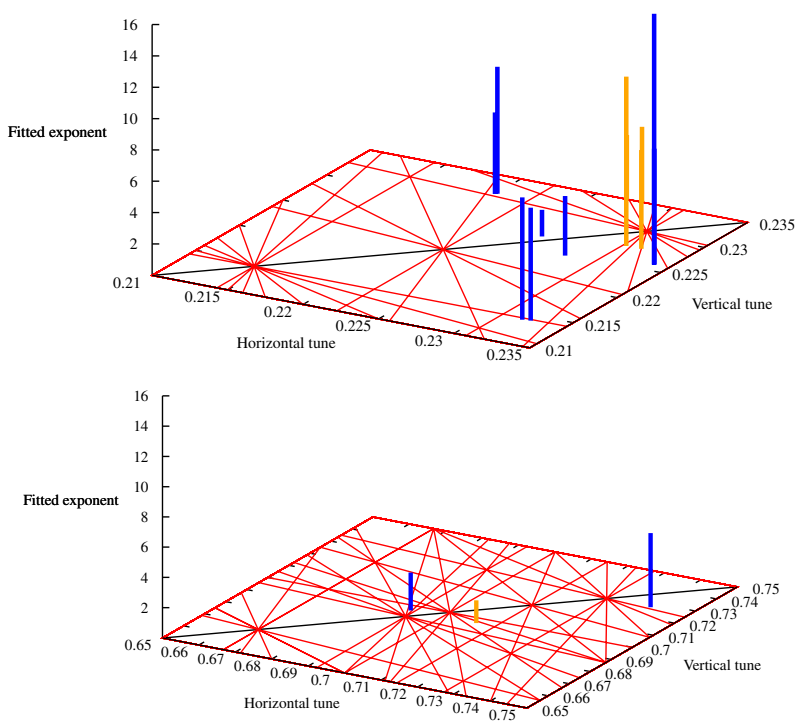

FIG. 14. Fitted exponents $p$ for long-range beam-beam experiments as a function of the ion tunes (top) and the proton tunes (bottom). The fitted exponents range from 1.7 to 16 . 


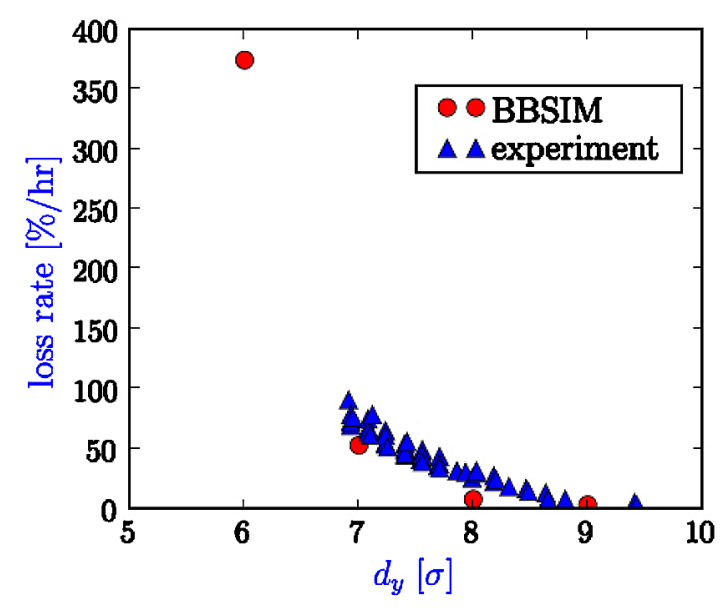

FIG. 15. Comparison of measured and simulated beam loss rate as a function of distance between wire and beam. Experiment with gold beam at store, wire strength of $125 \mathrm{Am}$ $[52,54]$.

luminosity lifetime of $10 \mathrm{~h}$ or less. Table III shows an amplitude range between 3.5 and $17 \sigma$. With the available amount of data no clear correlation can be established between this distance and the fitted coefficient $p$. In two cases the distance was found to be as large as or larger than $10 \sigma$, and most cases fall between 4 and $10 \sigma$. Operation with less than $5 \sigma$ separation appears to be difficult [51]. Note that the beam is sometimes used for multiple scans and that a large lifetime drop at large distances is more typical for previously unused beam (Table III).

One important goal of the experiments is to benchmark simulations. In several simulations the onset of large losses as a function of the distance between wire and beam was reproduced within about $1 \sigma[30,49,52-56]$. One such comparison is shown in Fig. 15.

\section{Long-range effects with head-on collisions}

End of physics fills were initially used to test the effect of the wires on colliding gold and deuteron beams (see Table III). It should be noted that the beam-beam parameter of proton beams in RHIC is approximately 3 times larger than the beam-beam parameter of heavy ion beams. The first dedicated experiment with protons to compare the effect of the wire on colliding beams and compensation of a single LR beam-beam interaction was conducted in 2009 at $100 \mathrm{GeV}$. Because of aperture considerations for decreasing $\beta^{*}$, the Blue wire was removed during the shutdown after the 2009 run and the Yellow wire was removed subsequently. Therefore, the experiments in 2009 serve as the final set of measurements for LR beam-beam with RHIC as a test bed. The relevant RHIC beam and lattice parameters are listed in Table VI for the experiments in 2009.

Prior to a long-range compensation attempt, a position scan of the wire on each beam was performed with a wire current of $50 \mathrm{~A}$. A $36 \times 36$ bunch pattern with six
TABLE VI. Relevant RHIC beam and lattice parameters for experiments with proton beams.

\begin{tabular}{lccc}
\hline \hline Quantity & Unit & Blue & Yellow \\
\hline Beam energy $E$ & $\mathrm{GeV}$ & 100 & \\
Rigidity $(B \rho)$ & $\mathrm{Tm}$ & 333.5 & \\
Number of bunches & $\ldots$ & 36 & \\
Number of colliding bunches & $\ldots$ & 30 & \\
Bunch intensity & $10^{11}$ & 1.7 & 1.7 \\
Normal emittance $\epsilon_{x, y}$ & $\mu \mathrm{rad}$ & 25,24 & 49,19 \\
Horizontal tune $Q_{x}$ & $\ldots$ & 28.691 & 28.232 \\
Vertical tune $Q_{y}$ & $\ldots$ & 29.688 & 29.692 \\
Chromaticities $\left(\xi_{x}, \xi_{y}\right)$ & $\ldots$ & $(+2,+2)$ & \\
$\beta_{x}$ at wire location & $\mathrm{m}$ & 1566 & 556 \\
$\beta_{y}$ at wire location & $\mathrm{m}$ & 576 & 1607 \\
\hline \hline
\end{tabular}

noncolliding bunches was chosen to enable a comparison of the lifetime in the presence of the wire between single beam and colliding beams simultaneously. The corresponding beam loss rates as a function of beam to wire separation on both colliding and noncolliding bunches were measured. The initial beam loss rates with colliding beams were stabilized to the nominal $10 \% / \mathrm{hr}$. The maximum total beam losses for the wire movements towards the beam at fixed current were constrained to $100 \%-150 \% / \mathrm{hr}$ for a very short period to avoid disrupting the beam quality significantly for subsequent measurements.

Figure 17 shows the evolution of the intensity between bunches with and without head-on collisions. It is evident that the bunches with the head-on collisions have a more severe effect from the LR forces of the wire. Several hypothesis can be formulated to explain the increased losses for bunches with head-on collision. The dynamic aperture for the bunches with head-on is significantly smaller than that of the single beam which could lead to the observed beam losses. It was also suggested by [57] that the addition of the head-on collisions enhances the diffusion leading to enhanced losses in the presence of long-range interactions. Figure 17 clearly shows a larger initial slope for bunch intensities with collisions. However, it is difficult to untangle the contribution from the reduced dynamic aperture as opposed to enhanced diffusion. The additional tune shift due to the wire along with large headon tune shift could lead to beam losses due to very limited tune space available. No tune optimization was performed during the experiment. The effect of the wire on the orbit can introduce a static offset between the two beams at the IP which is approximately proportional to the wire distance. A large offset due to the kick from the wire can lead to emittance blowup and beam losses [31]. The relative offset at the collision point during the wire scan with $50 \mathrm{~A}$ (see Fig. 16) is well below the $1 \sigma$ level which is very small. However, simulations to support each of the above hypotheses to explain its contribution towards observed losses is beyond the scope of this paper. 

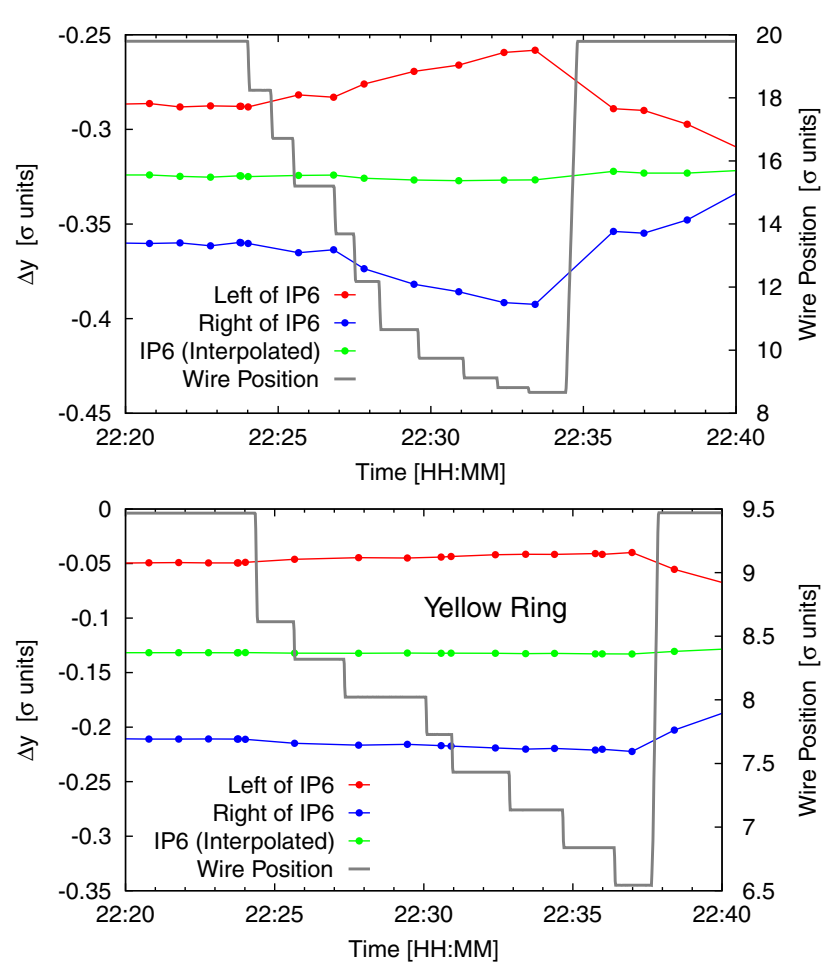

FIG. 16. Orbit offset at IP6 as a function of the wire position for Blue (top) and Yellow (bottom) rings with a current of $50 \mathrm{~A}$.
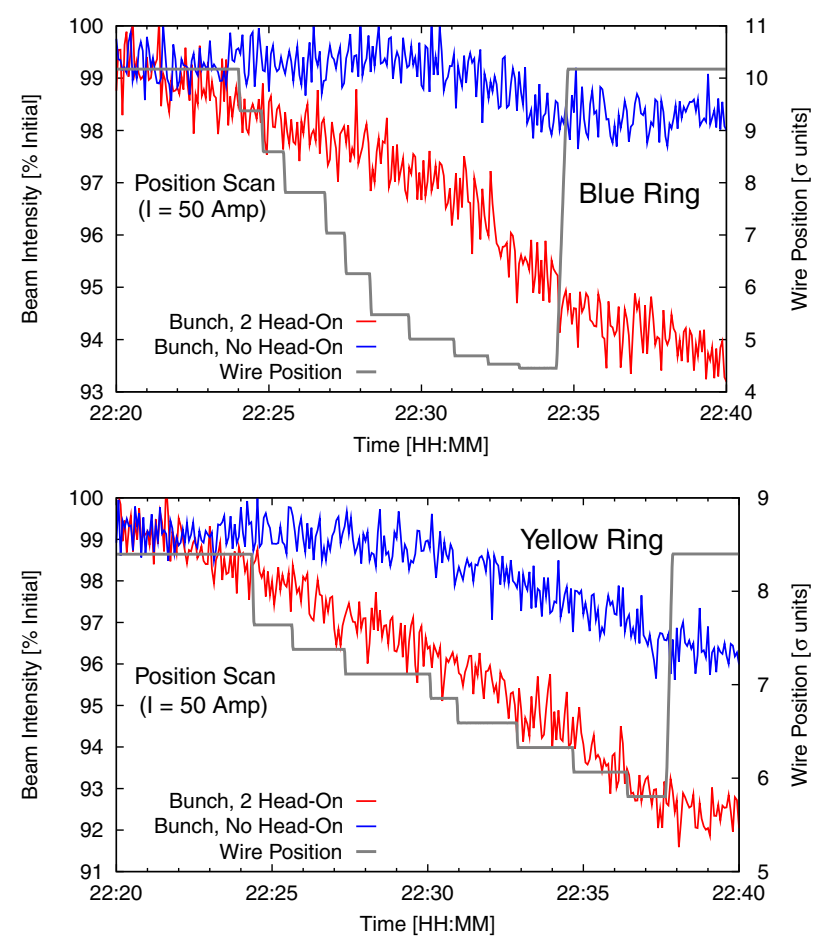

FIG. 17. Single bunch intensities as a function of wire position for Blue (top) and Yellow (bottom) rings with a current of $50 \mathrm{~A}$. Comparison between bunches with head-on and no head-on collision is shown.

\section{Single long-range and wire compensation}

The bunch spacing and the interaction region geometry in RHIC does not inherently have LR beam-beam interactions. It is therefore necessary to shift the collision point towards the DX magnet closest to the DC wires as noted before. This location enables for an artificially induced LR interaction between the two beams and simultaneously allows for a minimum phase advance between the LR interaction and DC wires (6 deg). Additionally, this location has sufficient aperture for an orbit scan with the range of interest $(3-10 \sigma)$. Figure 18 shows the trajectories of the Blue and Yellow rings with the LR interaction set at approximately $3.1 \sigma$.

The individual bunch intensities and beam losses were recorded during the position scan with the LR compensation [58]. Figure 19 shows the beam losses as a function of the wire position. In the Blue ring, the losses are always increasing as the wire approaches closer to the beam. Therefore, no evidence of compensation of the LR interaction from the Blue beam is visible. However, in the Yellow ring, the beam lifetime improved as the beam to wire distance approaches $3 \sigma$ (Fig. 19). Consecutive retractions and restoration of the beam to wire distance to $3 \sigma$ show similar improvement of the beam lifetime. This indicates a compensation of the effect of LR interaction by the DC wire.

In addition to beam losses, the individual bunch intensities with and without LR interactions and simultaneous compensation are shown in Fig. 20. Note that all 36 bunches experience the effect of the DC wire, but only 30 bunches experience LR interactions. Therefore, only bunches with a LR interaction can experience a compensation. In the Blue ring, the bunch intensity evolution is similar for bunches with and without LR compensation. Hence, only the effect from the wire is visible. The bunches with LR interaction and simultaneous compensation have reduced beam losses as compared to the bunches that only see the wire. This is consistent with the beam loss measurements (Fig. 19).

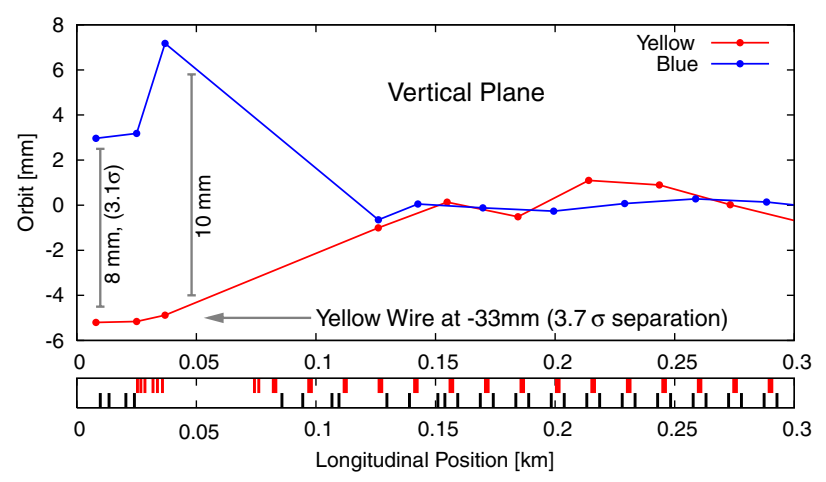

FIG. 18. Orbits right of IP6 for the Blue and the Yellow ring with the LR interaction setup near the DX magnet at approximately $3.1 \sigma$. 

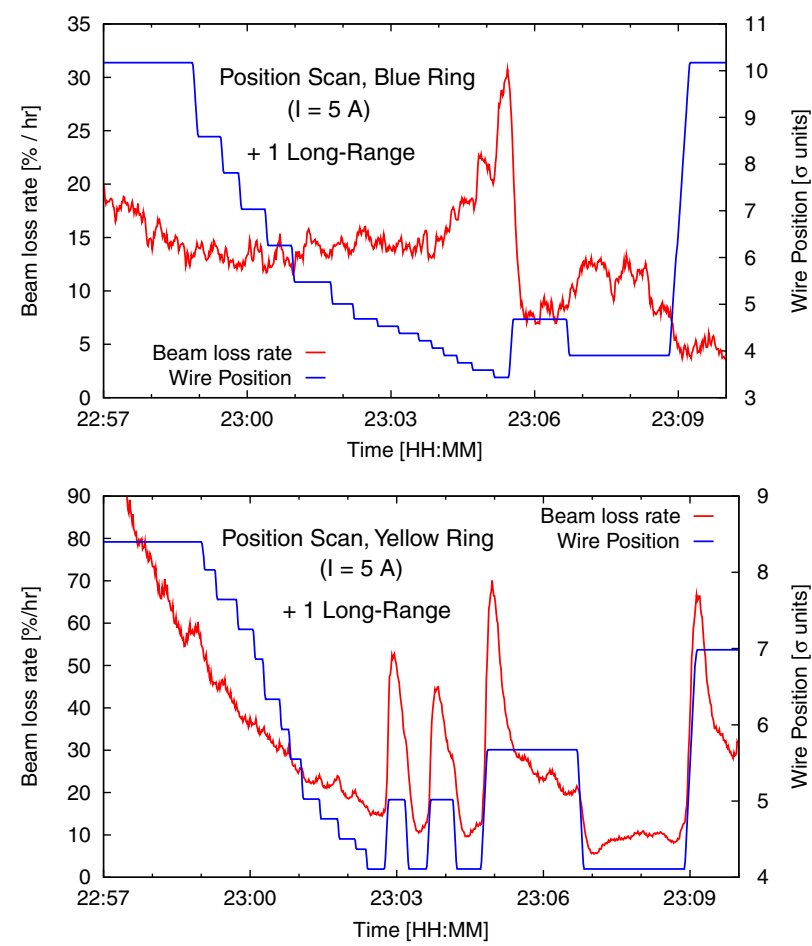

FIG. 19. Beam loss rate for a Blue (top) and a Yellow (bottom) bunch with one long-range interaction, and an additional wire interaction. The wire position varies, and the wire current is constant at $5 \mathrm{~A}$.
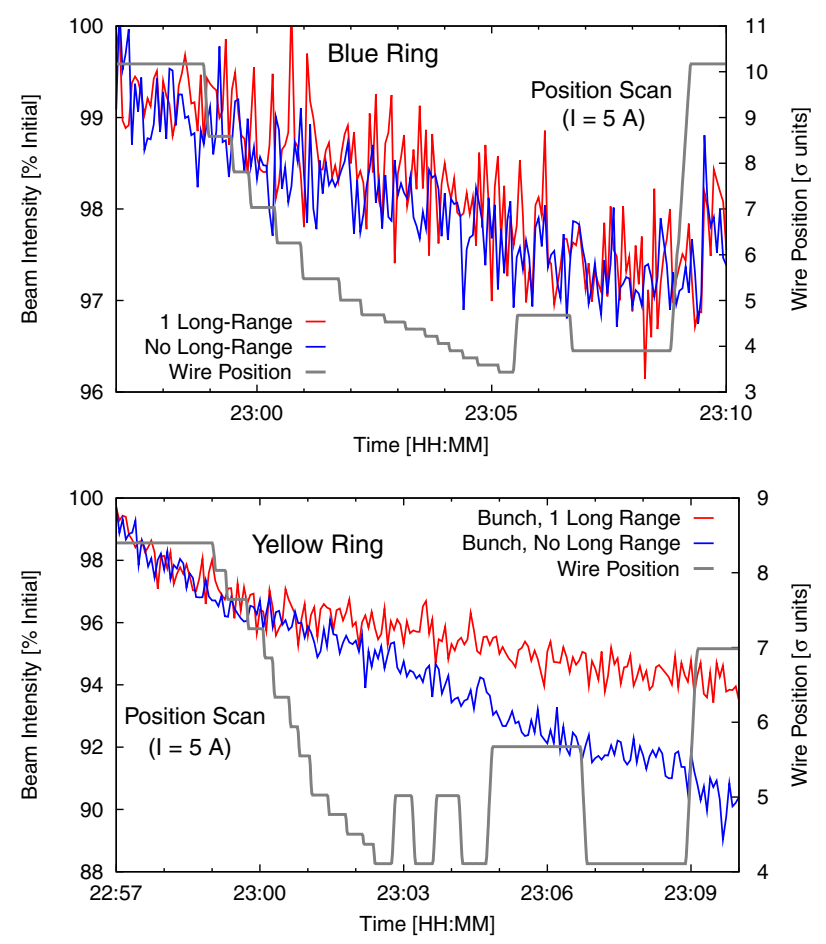

FIG. 20. Beam intensity comparison between bunches with a single long-range and no long-range interaction as a function of the wire position for Blue (top) and Yellow (bottom) rings with a wire current of $5 \mathrm{~A}$.

\section{SUMMARY}

Long-range beam-beam experiments were conducted in RHIC from 2005 to 2009. The motivation for these were twofold. First, the experimental data can benchmark simulation codes for situations of strong localized long-range beam-beam interactions as they will exist in the LHC. Second, the compensation of a single long-range beambeam interaction can be tested in a scheme that is also usable in the LHC.

These experiments complement the experience with long-range beam-beam interactions in the Sp $\bar{p} S$ and Tevatron, wire experiments in the SPS, and the partial long-range compensation in DAФNE. The RHIC wires created strong localized long-range beam-beam effects, comparable in strength to the effect expected in the LHC, with a beam that has a lifetime typical of hadron colliders, and including head-on beam-beam collisions. The observed orbit and tune changes due to the wire were as expected. The effect of the long-range beambeam interactions on the beam loss rate is sensitive to a number of beam parameters such as the tunes and chromaticities. Fitting the beam lifetime $\tau$ to an exponential function $\tau \propto d^{p}$ as a function of the distance $d$ between the beam and the wire, exponents $p$ in the range between 1.7 and 16 were found. Distances smaller than $5 \sigma$ created losses too large for collider operation. The experimentally observed distance from the wire to the beam at which large beam losses set in could be reproduced in simulations within $1 \sigma$. The beam lifetime with long-range interactions created by the wire was degraded further through head-on collisions. A single attempt to compensate long-range beam-beam interaction via a DC wire showed evidence of compensation.

\section{ACKNOWLEDGMENTS}

For discussions and help we are most thankful to collaborators within the U.S. LHC Accelerator Research Program as well as several people at various laboratories. Among these are O. Brüning, R. DeMaria, U. Dorda, W. Herr, A. Kabel, H.-J. Kim, J.-P. Koutchouk, C. Milardi, K. Ohmi, T. Pieloni, J. Qiang, F. Schmidt, T. Sen, G. Sterbini, and F. Zimmermann. This work was supported by Brookhaven Science Associates, LLC under Contract No. DE-AC02-98CH10886 with the U.S. Department of Energy, and in part by the U.S. LHC Accelerator Research Program.

[1] E. Keil, in Proceedings of the 1989 Particle Accelerator Conference, Chicago, IL (IEEE, New York, 1989), pp. 1731-1735.

[2] Y. Alexahin, in Proceedings of the 21st Particle Accelerator Conference, Knoxville, 2005 (IEEE, Piscataway, NJ, 2005), pp. 544-548. 
[3] J.-P. Koutchouk, in Proceedings Final CARE-HHH Workshop on Scenarios for the LHC Upgrade and Fair (HHH-2008, Chavannes-de-Bogis, Switzerland, 2008); W. Scandale and F. Zimmermann, Report No. CERN-2009004, edited by W. Scandale and F. Zimmermann, 2009; Report No. CARE-Conf-08-032-HHH, 2008.

[4] M. Jacob and K. Johnson, CERN Yellow Report No. 8423, 1984.

[5] J. Y. Hémery, A. Hofmann, J.-P. Koutchouk, S. Myers, and L. Vos, IEEE Trans. Nucl. Sci. 283 (1981).

[6] The CERN Study Group on New Accelerators, CERN Report No AR/Int. SG/64-9, 1964.

[7] L. R. Evans and J. Gareyte, in Proceedings PAC'83 (IEEE Trans. Nucl. Sci. 30, 2397 (1983).

[8] L. Evans, J. Gareyte, M. Meddahi, and R. Schmidt, in Proceedings of the 1989 Particle Accelerator Conference, Chicago, IL (Ref. [1]), pp. 1403-1405.

[9] K. Cornelis, M. Meddahi, and R. Schmidt, Proceedings EPAC'90 (1990), pp. 1670-1672.

[10] K. Cornelis, in Proceedings LHC'99 (CERN-SL-99-039 AP, 1999).

[11] X. Zhang, T. Sen, V. Shiltsev, M. Xiao, Y. Alexahin, F. Schmidt, and F. Zimmermann, in Proceedings of the 20th Particle Accelerator Conference, Portland, OR, 2003 (IEEE, New York, 2003), pp. 1757-1759.

[12] V. Shiltsev, Y. Alexahin, V. Lebedev, P. Lebrun, R.S. Moore, T. Sen, A. Tollestrup, A. Valishev, and X. L. Zhang, Phys. Rev. ST Accel. Beams 8, 101001 (2005).

[13] A. Valishev, in Proceedings of the 11th European Particle Accelerator Conference, Genoa, 2008 (EPS-AG, Genoa, Italy, 2008), pp. 2937-2941.

[14] W. Fischer, M. Blaskiewicz, J. M. Brennan, P. Cameron, R. Connolly, C. Montag, S. Peggs, F. Pilat, V. Ptitsyn, S. Tepikian, D. Trbojevic, and J. van Zeijts, in Proceedings of the 20th Particle Accelerator Conference, Portland, OR, 2003 (Ref. [11]), pp. 135-137.

[15] V. Ptitsyn et al., in Proceedings of the 10th European Particle Accelerator Conference, Edinburgh, Scotland, 2006 (EPS-AG, Edinburgh, Scotland, 2006), pp. 592-594.

[16] W. Herr, in Proceedings of the Particle Accelerator Conference, San Francisco, CA, 1991 (IEEE, New York, 1991), pp. 1068-1070.

[17] N. Gelfand, C. Johnstone, T. Sen, and W. Wan, in Proceedings of the 18th Particle Accelerator Conference, New York, 1999 (IEEE, New York, 1999), pp. 1677-1679.

[18] J. Gareyte, in Proceedings LHC'99 (CERN-SL-99-039 AP, 1999), pp. 28-32.

[19] M. A. Furman and W. C. Turner, in Proceedings of the European Particle Accelerator Conference, Vienna, 2000 (EPS, Geneva, 2000), pp. 1196-1189.

[20] H. Grote, in Proceedings of the European Particle Accelerator Conference, Vienna, 2000 (Ref. [19]), pp. 1202-1204.

[21] L.H.A. Leunissen, H. Grote, and F. Schmidt, in Proceedings of the European Particle Accelerator Conference, Vienna, 2000 (Ref. [19]), pp. 1208-1210.

[22] M. P. Zorzano and T. Sen, in Proceedings of the European Particle Accelerator Conference, Vienna, 2000 (Ref. [19]), pp. 1226-1228.
[23] M. P. Zorzano and F. Zimmermann, in Proceedings of the European Particle Accelerator Conference, Vienna, 2000 (Ref. [19]), pp. 1229-1231.

[24] W. Herr, in Proceedings of the European Particle Accelerator Conference, Vienna, 2000 (Ref. [19]), pp. 1630-1632.

[25] O. Bruning, P. Collier, P. Lebrun, S. Myers, R. Ostojic, J. Poole, and P. Proudlock, Report No. CERN-2004-003, 2004.

[26] F. Zimmermann, in Proceedings of the 2007 Particle Accelerator Conference, Albuquerque, New Mexico (IEEE, New York, 2007), pp. 714-718.

[27] J.-P. Koutchouk, in Proceedings of the 2007 Particle Accelerator Conference, Albuquerque, New Mexico (Ref. [26]), pp. 3387-3389.

[28] G. Sterbini and G. Tommasini, in Proceedings of the 11th European Particle Accelerator Conference, Genoa, 2008 (Ref. [13]), pp. 2461-2463.

[29] K. Ohmi, in Proceedings of the 11th European Particle Accelerator Conference, Genoa, 2008 (Ref. [13]), pp. 2593-2595.

[30] U. Dorda, Ph.D. thesis, Vienna University of Technology, Austria, 2008.

[31] T. Pieloni, Ph.D. thesis, Ecole Polytechnique Federale de Lausanne, Switzerland, 2008.

[32] U. Dorda and F. Zimmermann, in Proceedings of the 11th European Particle Accelerator Conference, Genoa, 2008 (Ref. [13]), pp. 2245-2247.

[33] W. Herr, in Proceedings of the 2010 Evian Workshop on LHC Commissioning, CERN, 2010.

[34] V. Shiltsev, V. Danilov, D. Finley, and A. Sery, Phys. Rev. ST Accel. Beams 2, 071001 (1999).

[35] J.-P. Koutchouk, in Proceedings of the 19th Particle Accelerator Conference, Chicago, Illinois, 2001 (IEEE, Piscataway, NJ, 2001), pp. 1681-1683.

[36] U. Dorda, F. Zimmermann, W. Fischer, and V. Shiltsev, in Proceedings of the 2007 Particle Accelerator Conference, Albuquerque, New Mexico (Ref. [26]), pp. 1589-1591.

[37] T. Sen and B. Erdelyi, in Proceedings of the 21st Particle Accelerator Conference, Knoxville, 2005 (Ref. [2]), pp. 2645-2647.

[38] C. Milardi, D. Alesini, M. A. Pregner, P. Raimondi, M. Zobov, and D. Shatilov, in Proceedings of the 10th European Particle Accelerator Conference, Edinburgh, Scotland, 2006 (Ref. [15]), pp. 2808-2810.

[39] W. Fischer, O. Brüning, J.-P. Koutchouk, F. Zimmermann, T. Sen, V. Shiltsev, K. Ohmi, M. Furman, Y. Cai, and A. Chao, informal note BNL C-A/AP/291; ICFA Beam Dynamics Newsletter No. 44, pp. 220-225; Proceedings of BEAM'07 (Reports No. CERN-2008-005 and No. CARE-Conf-08-004-HHH, 2008).

[40] J.-P. Koutchouk, J. Wenniger, and F. Zimmermann, in Proceedings of the 9th European Particle Accelerator Conference, Lucerne, 2004 (EPS-AG, Lucerne, 2004), pp. 1936-1938.

[41] F. Zimmermann, J.-P. Koutchouk, F. Roncarolo, J. Wenninger, T. Sen, V. Shiltsev, Y. Papaphilippou, in Proceedings of the 21st Particle Accelerator Conference, Knoxville, 2005 (Ref. [2]), pp. 686-688.

[42] U. Dorda, J.-P. Koutchouk, R. Tomas, J. Wenniger, F. Zimmermann, R. Calaga, and W. Fischer, in Proceedings 
of the 11th European Particle Accelerator Conference, Genoa, 2008 (Ref. [13]), pp. 3176-3178.

[43] W. Fischer, R. Alforque, H. C. Hseuh, R. Lambiase, C. J. Liaw, G. Miglionico, T. Russo, J.-P. Koutchouk, F. Zimmermann, and T. Sen, informal note BNL C-A/AP/ 236, 2006.

[44] W. Fischer, R. Calaga, U. Dorda, J.-P. Koutchouk, F. Zimmermann, V. Ranjbar, T. Sen, J. Shi, J. Qiang, and A. Kabel, in Proceedings of the 10th European Particle Accelerator Conference, Edinburgh, Scotland, 2006 (Ref. [15]), pp. 2158-2160.

[45] F. Zimmermann, in Proceedings of the Beam-Beam Workshop at Fermilab (Report No. FERMILAB-Conf01/390-T and CERN LHC Project Report No. 502, 2001.

[46] R. Calaga et al., ICFA Beam Dynamics Newsletter 52, 95 (2011).

[47] W. Fischer, N. Abreu, R. Calaga, G. Robert-Demolaize, H.-J. Kim, T. Sen, J. Qiang, A. C. Kabel, U. Dorda, J.-P. Koutchouk, and F. Zimmermann, in Proceedings of the 2007 Particle Accelerator Conference, Albuquerque, New Mexico (Ref. [26]), pp. 1859-1861.
[48] T. Sen and B. Erdelyi, in Proceedings of the 8th European Particle Accelerator Conference, Paris, 2002 (EPS-IGA and CERN, Geneva, 2002), pp. 1247-1249.

[49] H. J. Kim and T. Sen, in Proceedings of the 2007 Particle Accelerator Conference, Albuquerque, New Mexico (Ref. [26]), pp. 3492-3494.

[50] F. Zimmermann (private communication).

[51] N. Abreu, Proceedings BEAM'07 (Reports No. CERN2008-005 and No. CARE-Conf-08-004-HHH, 2008).

[52] H. J. Kim, T. Sen, N.P. Abreu, and W. Fischer, Proceedings HB2008, Nashville, Tennessee, 2008.

[53] H. J. Kim, T. Sen, N. P. Abreu, and W. Fischer, in Proceedings of the 11th European Particle Accelerator Conference, Genoa, 2008 (Ref. [13]), pp. 3119-3121.

[54] H.-J. Kim, T. Sen, N. Abreu, and W. Fischer, Phys. Rev. ST Accel. Beams 12, 031001 (2009).

[55] H. J. Kim, T. Sen, and W. Fischer, in Proceedings IPAC10, Kyoto, Japan, 2010, pp. 2072-2074.

[56] A. Kabel (private communication).

[57] Referee A, 2011.

[58] R. Calaga, W. Fischer, and G. Robert-Demolaize, in Proceedings IPAC10, Kyoto, Japan, 2010, pp. 510-512. 